Ivana R. Mali*

\title{
POLISEMIJA U KOMPJUTERSKOJ TERMINOLOGIJI ARAPSKOG JEZIKA
}

\begin{abstract}
$\mathrm{U}$ radu se proučava polisemija kod arapskih kompjuterskih termina. Za razliku od tradicionalne teorije terminologije, koja se bavi ,idealnim” terminima, lišenim polisemije, u proučavanju zauzimamo sociokognitivni pristup,prema kom se polisemija kod termina tretira kao normalna pojava. Analiza korpusa arapskih kompjuterskih termina je pokazala da postoji više uzroka nastanka polisemije kod njih. Ovi uzroci se mogu svesti na: metodologiju u tvorbi termina, upotrebu termina u kontekstu i nepoklapanje pojmovnih sistema, uz nerazumevanje odnosa među pojmovima. Kao rezultat ovih uticaja, javljaju se tri različita tipa polisemnih terminoloških jedinica: termini koji imaju bar dva značenja u kompjuterskom terminološkom sistemu; termini koji imaju bar jedno značenje u kompjuterskoj terminologiji, a drugo u nekom drugom terminološkom sistemu i termini koji imaju bar jedno terminološko, a drugo opštejezičko značenje.
\end{abstract}

Ključne reči: arapski jezik, polisemija, kompjuterska terminologija

\section{Teorijska osnova}

Polisemija ili višeznačnost (ar. ta'addudal-ma‘ānī) je ,sposobnost lekseme da se realizuje u više značenja, da ima više semantičkih realizacija", ističe DarinkaGortan-Premk (2004: 38). Prema tradicionalnoj teoriji terminologije, terminološka polisemija je retka i nepoželjna pojava, iako se u opštem jeziku ova sposobnost smatra pozitivnom i veoma je ustaljena.Tradicionalna teorija terminologije se bavi ,idealnom“ terminologijom, u kojoj nema mesta polisemiji,ističućinedvosmislenost kao važnu osobinu termina. Prema ovoj teoriji, termini su jednoznačni i otporni na uticaj konteksta, jer su nastali konvencionalnim putem i eksplicitno su definisani. Međutim, po-

Studentski trg 3, 11000 Beograd. ivanamali@fil.bg.ac.rs 
stoje i suprotna mišljenja o pitanju višeznačnosti kod termina. Polisemija se nikada ne može potpuno eliminisati, jer je priroda termina dvojaka, smatra Darinka Gortan-Premk. S jedne strane, termini pripadaju određenom terminološkom sistemu, gde teže jednoznačnosti, a s druge strane pripadaju opštem jezičkom fondu, pa teže razvijanju višeznačnosti (2004: 119).

Suprotno mišljenju o težnji termina ka jednoznačnosti, predstavnici novije škole, koja zauzima sociokognitivni pristup u opisu terminologije,smatraju da terminološka jednoznačnost nije neophodna, da nije česta $i$ da je neprirodna - predstavnici ove škole se zalažu za izučavanje sinonimije, polisemije i figurativnog jezika u terminologiji (Temmerman, 2000: 14; Šipka, 2006: 153-155). U knjizi Towards New Ways of Terminology Description, predstavnica ove škole, Rita Temmerman, razmatra punovažnost tradicionalne teorije terminologije, izvodeći zaključak da polisemija funkcioniše u specijalnim jezicima i da je stoga ona „korisna“ i ,značajna“. Predstavnici ove teorije polisemiju smatraju jednim od najproduktivnijih načina da se proširi terminološki fond neke naučno-stručne oblasti i vide je kao manifestaciju jezičke ekonomije u terminosistemu i jeziku uopšte.

Da bi se razumela pojava polisemije u terminologiji, neophodno je proučavati termine u tekstu, njihovu dinamiku i razvoj. Dok je za tradicionalnu terminologiju važna sinhronija (ona se ne bavi razvojem jezika $i$ terminosistema), sociokognitivni pristup terminologiji podrazumeva da se pojmovi i njihove oznake menjaju tokom vremena,pa se predlaže proučavanje termina iz dijahronijske perspektive (Temmerman, 2000: 14-15; Šipka, 2006: 153-154). Šipka zapaža da tradicionalni i sociokognitivni pristup nisu suprotstavljeni i da u proučavanju terminosistema ima mesta za oba. Tradicionalni pristup je primereniji u proučavanju terminoloških baza podataka, rečnika i sl., dok sociokognitivni pristup bolje objašnjava upotrebu termina u kontekstu i njihove promene u vremenu (2006: 155).

Cabré navodi da bi se, zbog prirode terminoloških sistema, terminološka polisemijamogla zapravo smatrati homonimijom. Termini koji se odnose na jedan pojam u jednoj, a na drugi pojam u nekoj drugoj terminologiji ili uopšte upotrebnom jeziku mogu se tretirati kao homonimi, jer se javljaju u više različitih sistema, u kojima označavaju različite pojmove (1999: 108). Zbog toga Cabré smatra da je homonimija mnogo češća u terminologiji, nego u opštem leksikonu, dok se polisemija češće javlja u leksikografiji. Po ovoj logici, svaki termin koji se po principu analogije prenosi iz jedne u drugu oblast je homonim (Cabré, 1999: 111). Darinka 
Gortan-Premk je bliža drugom shvatanju, prema kom se ovakvi termini smatraju ,različitim pojmovnim vrednostima istoga termina“, pa je reč o polisemiji (2004: 120).

\section{Metodologija rada}

Što se tiče glavnog predmeta našeg interesovanja ovde, kompjuterskih termina na arapskom jeziku, ovaj rad se zasniva na analizi korpusaod oko hiljadu terminoloških jedinica, koje se frekventno realizuju u pisanom $\mathrm{i} / \mathrm{ili}$ usmenom diskursu. Termini su ekscerpiraniiz relevantne literature na arapskom jeziku (priručnici, udžbenici, časopisi i sl.), sa veba (forumi, društvene mreže, popularni članci i sl.), iz kompjuterskih programa/aplikacija i televizijskih emisija koje se bave savremenim tehnologijama,uz konsultacije sa nekoliko govornika arapskog jezika kao maternjeg. Kompjutersko terminološko polje je ogromno, pa smo se morali ograničiti na uzorak sastavljen od termina po vlastitom izboru, nadajući se da će on biti reprezentativan za čitav kompjuterski terminološki sistem. Termini su birani tako da budu što raznovrsniji, pa tako rečnik uključuje: termine za hardverske komponente, softverske termine, termine vezane za informacione tehnologije, termine koji se odnose na veb i internet, kao i neke vlastite imenice (nazive kompjuterskih programa, programskih jezika i sl).

Prikupljanje ovog korpusa termina obavljeno je sa izrazito deskriptivnom svrhom, bez namere da se izvrši bilo kakva preskripcija tj. nametne upotreba određenih ,idealnih“ termina. Korpus je sastavljen radi različitih lingvističkih proučavanja kompjuterskog terminosistema, a jedno od njih čine svakako i semantička proučavanja.Prilikom rada na korpusu primećeno je da se u nekim slučajevima bar dva različita pojma označavaju istim terminom, što je podstaklo naše interesovanje za uzroke nastanka polisemije u ovom terminosistemu...

\section{Rezultati istraživanja}

U arapskom svetu jezički purizam je veoma izražen, pa se adaptacija termina stranog porekla izbegava kad god je to moguće. Insistiranje arap- 
skih jezičkih stručnjaka na traženju domaćeg ekvivalenta za svaki termin predstavlja jedan od glavnih razloga za nastanak polisemije u terminološkom sistemu, jerdomaće reči u jeziku obično imaju više značenja odstranih. Kada termini stranog porekla uđu u jezik, oni ulaze „kao nominacione jedinice sa semantičkim sadržajem u kome je izražena pojmovna vrednost, dok ostali elementi značenja gotovo izostaju“, zaključuje Darinka Gortan-Premk, ističući da to ima za posledicu umanjenu sposobnost polisemantičke disperzije (2004: 41). Zbog toga je u arapskoj kompjuterskoj terminologiji broj višeznačnih termina znatno veći, nego što bi bio u terminosistemu u kom dominiraju kompjuterski anglicizmi. Na primer, termin kumbyūtar (eng. computer), koji je u arapski došao iz engleskog jezika, je jednoznačan - označava isključivo elektronski uređaj koji može da prima informacije u određenom obliku i vrši niz operacija u skladu sa nizom instrukcija ili programa, da bi proizveo rezultat u vidu informacija. Da bi se osmislio arapski ekvivalent za ovaj anglicizam, osmišljeno je više domaćih termina,pretežno od korena *hsb, koji nosi ideju ,računanja”. Među njima se javlja i višeznačni termin hạsiba, kojim se označavaju i calculator (/āla/ hạsiba) i computer (hạsiba /āliyya).

Lekseme mogu imati različitu sudbinu u vezi sa višeznačnošću, jer se nekima od njih vremenom uvećava broj značenja. Govoreći o najčešćim mehanizmima nastanka polisemije u jeziku uopšte, Rajna Dragićević ističe da su to metafora, metonimija, sinegdoha i platisemija “ (2010: 127). Što se tiče termina, oni teže ostvaruju figurativna značenja od reči iz opšteg fonda. Prenos imena sa nekog opšteupotrebnog pojma na pojam iz određene naučno-stručne oblasti obično se vrši na osnovu sličnosti ili bliskosti između dva pojma. „Prvo se uspostavi logička veza između predmeta koji treba imenovati s nekim drugim predmetom koji ima zasebnu reč, a zatim se naziv predmeta s imenom prenosi na predmet bez imena", ističe Dragićević (2010: 131). Na arapskom jeziku se figurativna upotreba reči u tvorbi termina naziva terminom al-mağăz. Iako se ovaj mehanizam često poistovećuje sa metaforom, on označava bilo koju stilsku figuru. Zapravo, u tvorbi termina najčešćese koristi metafora(ar. al-mağăz al-'isti 'äriyy), a ređei sinegdoha (ar. al-mağăz al-mursal),što ima za posledicu nastanak polisemnih termina sa bar jednim opštejezičkim i jednim terminološkim značenjem.

Metaforičko prenošenje se zasniva na sličnosti, tako što „[p]ojedini novi predmeti dobijaju postojeće oznake drugih predmeta s kojima su u 
nekakvoj vezi“ (Dragićević 2010: 130). Darinka Gortan-Premk ističe da "[t]ermini ne mogu širiti svoju semantičku strukturu metaforičkim putem" (2004: 119), ali moguće je metaforičko prenošenje sa reči opšteg fonda na termin. ,Recimo, ulaskom kompjutera u svakodnevni život leksema miš dobila je jedno novo značenje: mala mobilna sprava kojom se kontrolišu pokreti kursora na kompjuterskom monitoru“ (Dragićević 2010: 130). Na isti način je i arapska reč fa 'ra, koja označava miša, dobila novo značenje. Do metaforičkog prenošenja je zapravo došlo u engleskom jeziku, na osnovu sličnosti između životinje miša i sprave koja se koristi da olakša rad na kompjuteru, a potom se ovaj termin preneo i na druge jezike, kao kalk.

U kompjuterskoj terminologiji arapskog jezika postoji mnoštvo polisemnih termina koji su nastali upravo na ovaj način. Recimo, reč šabaka je pored opštejezičkog značenja dobila i terminološko - označava skup dokumenata u elektronskom obliku, koji su međusobno povezani, nalik na mrežu (en. web). Na isti način je reč zirr pored svog opštejezičkog značenja dobila i jedno značenje u oblasti kompjuterske terminologije - na osnovu sličnosti sa pravim dugmetom, ova reč postaje oznaka za grafički element koji se javlja na korisničkom interfejsu i na koji se može kliknuti (en. button). Pomenućemo ovde još i termin qarșana, koji u opštem jeziku označava čin napadanja i pljačkanja brodova na moru, dok u računarstvu označava ilegalno kopiranje kompjuterskih programa, a odnosi se i na ilegalnu upotrebu tuđeg stvaralaštva uopšte, poput muzike, filmova i slično (en. piracy). Ovde je takođe došlo do metaforičkog prenošenja, jer je u oba slučaja reč o ilegalnom prisvajanju.

Kako ističe R. Dragićević: „Govoreći i pišući koristimo gotove derivate, ali i ustaljene tvorbene modele. Oni se stalno mogu iznova koristiti za imenovanje novih pojava“" (2010: 131). Tako će, na primer, predmeti i ljudi koji nešto prikazuju/izlažu dobiti oznaku izlagač. Na arapskom se reč 'ārid odnosi na ljude i koristi da označi izvođača, izlagača, interpretatora i slične pojmove. Što se tiče kompjuterske terminologije, ova reč je poslužila kao oznaka za aplikaciju koja prikazuje određeni fajl (en. viewer). Termin qāri' se u opšteupotrebnom jeziku odnosi na ljude - njegovo značenje je čitalac, recitator. U kompjuterskoj terminologiji ovaj termin je poslužio kao oznaka za aplikaciju koja olakšava čitanje određenih fajlova (en. reader). Leksema $\underline{h} \bar{a} d i m$ ima opštejezičko značenje koje se takođe odnosi na ljude - sluga, (po)služitelj, onaj koji je u službi i sl. U kompjuterskoj 
terminologiji ova reč dobija značenje sistema koji pruža usluge drugim kompjuterskim sistemima (en. server).

Do polisemije kod termina dolazi i u slučajevima kada se "jedan isti termin javlja u različitim terminološkim sistemima i sa različitim pojmovnim vrednostima" (Gortan-Premk, 2004: 120). I u ovom slučaju dolazi do metaforičkog prenošenja. Cabré kao primer navodi termin virus - ovaj termin u medicini označava patogen, naročito neki iz grupe ultramikroskopskih patogena, koji se reprodukuju samo u živim ćelijama, dok u računarstvu označava program koji se sam reprodukuje $i$ koji je dizajniran sa namerom da poremeti rad jednog kompjutera ili kompjuterske mreže (1999: 109). Isti mehanizam se preneo i na arapski jezik, gde se terminfayrūskoristi i u medicini i u računarstvu. Sličnu sudbinu imali su i drugi termini, koji su preuzeti iz različitih naučno-stručnih oblasti, da bi postali oznaka za neki pojam iz oblasti računarstva. Na primer, termin istīrād (en. import) koji je vezan za ekonomiju i trgovinu, gde označava prenos proizvoda iz jedne u drugu zemlju radi prodaje, u računarstvu označava prenos informacija iz jednog sistema, programa i sl. u drugi.

Kod nekih termina nije na prvi pogled jasno da li su nastali terminologizacijom reči iz opšteg fonda ili pak preuzimanjem termina iz druge oblasti, zbog bogate polisemantičke strukture. Na primer, leksema miftāḥ može biti i opšteupotrebna reči termin koji se javlja u nekoliko terminoloških sistema. U opštem jeziku on označava ključ, alatku za zaključavanje i otključavanje, doku mehanici označava /francuski/ ključ, vrstu alata koja služi za šrafljenje i može se podesiti prema veličini šrafa (ar. miftāḥ 'inklīziyy). U elektromehanici ovaj termin označava prekidačza napajanje strujom (ar. miftāh kahra$b \bar{a}$ 'iyy), dok u kompjuterskoj terminologiji označava taster na tastaturiili polje koje služi za identifikaciju zapisa u bazama podataka (en. key).

Što se tiče polisemije unutar kompjuterskog terminološkog sistema u arapskom jeziku, do nje obično dolazi kada se jedna arapska reč koristi kao prevod dvaju ili više engleskih termina sličnog značenja. Jedan od glavnih razloga za ovu pojavu je taj što je prvo nastao jedan pojam, a termin za njega je postao ustaljen u upotrebi. Zatim je nastao i drugi pojam, za koji nije bilo boljeg termina, do onog koji je već upotrebljen za prvi pojam.

$\mathrm{Na}$ primer, termin taḥmīlse često koristi kao ekvivalent engleskih termina loading, downloading i uploading, koji imaju slična značenja.Dok se downloading odnosi na preuzimanje tj.prenošenjepodataka sa nekog 
udaljenog kompjutera na lokalni, termin uploading ima suprotno značenje, otpremanje tj. prenošenje podataka u obrnutom smeru - sa lokalnog kompjutera na udaljeni. Termin loading označava proces koji izvršava aplikacija kada otvara (učitava) neki fajl ili program. U arapskom jeziku je pronađena sličnost između ova tri pojma i korena *hml koji označava (pre)nošenje, transport i sl.

Primer koji smo naveli se javlja u diskursu među nestručnjacima. Kada je u pitanju terminologija koju koristi softverska firma Microsoftu svojim proizvodima namenjenim arapskom tržištu, razlika između termina download i upload ipak postoji! Oni su prevedeni terminima tanzīl i taḥmīl, respektivno (u ovom slučaju termin download označen je korenom *nzl koji označava silaženje, spuštanje). Međutim,u proizvodima ove firme nema razlike između terminauploading i loading - za oba se koristi isti arapskiekvivalent, taḥmīl. Ovi primeri pokazuju da je teško izbeći polisemiju, čak i kad se terminologija izgrađuje planski, unutar jedne softverske firme koja poseduje onlajn bazu podataka svih termina koji se javljaju u njenim proizvodima na različitim jezicima.

U terminološkoj bazi podataka firme Microsoft (www.microsoft. com/Language/en-US/Search.aspx) naišli smo i na druge slučajeve polisemije, koje smo prethodno uočili u i pisanom diskursu na arapskom jeziku. Na primer, termin $d a \dot{g} t ̦$ (od korena * $d \dot{g} t$ koji nosi ideju,,sabijanja“, ,,presovanja“, „pritiskanja“" i sl.) služi kao prevod engleskog termina compress, koji označava komprimovanje tj. smanjivanje veličine podataka. Isti arapski termin koristi se kao prevod engleskog kompjuterskog termina press, koji označava pritiskanje /tastera/ (en. press).

U ovom kontekstu, navešćemo i leksemumash (od korena *msh, koji nosi ideju,,brisanja“, „glačanja“, „poliranja“, „,̌išćenja“, „uklanjanja“ i sl.). Njome je preveden termin clear, koji označava uklanjanje ili brisanje nekog podatka $i$ sl., a istom rečju preveden je i termin scan, koji označava pretvaranje teksta ili fotografije u digitalnu formu pomoću skenera.

Navešćemo još i primer arapske lekseme mu'āliğ (od korena * 'lğ, koji ima bogatu polisemantičku strukturu: „lečiti“, „obnoviti“, „praviti“, „obavljati“, „,vršiti“, „,rešavati““...). Ova leksema poslužila je kao prevod termina processor, kraćeg naziva za centralnu jedinicu za obradu, uređaja koji se nalazi u kompjuteru i izvršava naredbe kompjuterskih programa. Ista arapska leksema služi kao prevod termina wizard, koji označava program koji pomaže korisniku na neki način, recimo da instalira neku aplikaciju. 
U razloge za nastanak polisemije možemo svrstati i nepoklapanje pojmovnih sistema u dvama jezicima, što se najčešće javlja kao posledica prevođenja sa različitih jezika-izvora i/ili usled nerazumevanja logičkih/ ontoloških odnosa među pojmovima. Sistem pojmova bilo koje oblasti potpuno je nezavisan od terminološkog sistema, ali se odnosi koji postoje u pojmovnom sistemu mogu preslikati i na sistem termina. Uzmimo za primer pojmoveračunarstvai informatike, koji su povezani ontološkim odnosom, tipa deo-celina. Računarstvo (en. computer sceince) je deo informatike (en. information science, informatics) - dok računarstvo predstavlja disciplinu koja se bavi čuvanjem, obradom i prenosom podataka pomoću računara, informatika se odnosi na čuvanje, obradu i prenos podataka uopšte. Reč informatika vodi poreklo iz francuskog jezika, gde je od reči l'information i l'automatiqueskovan termin l'informatique. Ovaj termin je stvoren sa ciljem da zameni anglicizam data processing, ali je potom u neanglofonim sredinama postao veoma popularan kao zamena za engleski termin computer science (Vitas, Krstev i dr., 1996: 149). Višeznačnost ovog termina javlja se i u arapskom jeziku -termin l'informatique je na arapski preveden kao ma 'lümātiyya, aanalizom upotrebe ovog termina pokazalo se da se on ne odnosi samo na obradu podataka/informatiku, nego i na računarstvo. Drugim rečima, ovde je došlo do prenošenja po principu sinegdohe - nazivanja dela terminom za celinu. O tome svedoči činjenica da je jedna od najvažnijih arapskih institucija koje se bave terminologijom, Koordinacioni biro za arabizaciju u Rabatu,svojevremeno objavio englesko-francusko-arapski rečnik pod nazivom al-Mu '̆gam al-muwaḥhad li mușțalahāat al-ma 'lümātiyya (en. The Unified Dictionary of Computer Science Terms). Iako se iz ovog primera jasno vidi da se al-ma 'lūmātiyya tretira kao ekvivalent engleskog termina computer science, Biro nije uvek dosledan ovom terminološkom rešenju. Isti Biro u svojoj elektronskoj banci termina, kao ekvivalent za engleski termin computer science navodi francuski ekvivalent informatique i arapski termin ilm al-hāsū $b$, a sve to spada u oblast nazvanu terminomal-ma 'lümātiyya.

Prevođenje termina sa polisemijom u engleskom jeziku, može dovesti do polisemije i u arapskom, o čemu svedoči sledeći primer sinegdohe. Nestručnjaciobično ne prave razliku između fizičke mreže međusobno povezanih kompjutera,koju nazivamo Internet i sistema međusobno povezanih, hipertekstualnih dokumenata koji se nalaze na internetu, a koji se označavaju terminom World Wide Web. Iako ova dva pojma stoje u odnosu 
deo-celina, gde je Internet celina, aWorld Wide Web deo, laici ih često nazivaju istim imenom - internet, što znači da se deo imenuje celinom. Ovaj slučaj se iz engleskog preneo i na arapski jezik, gde se termin al-'intarnit često koristi umesto termina wīb. O ovoj pojavi, između ostalog, svedoči nedavno održana manifestacija pod nazivom Arabic Web Days, čiji arapski naziv glasi 'Ayyām al-'intarnit al- 'arabiyy (www.arabicwebdays.com).

\section{Zaključak}

Analizom korpusa arapskih kompjuterskih termina utvrđeno je dakod njih postoji više uzroka nastanka polisemije. Ovi uzroci se mogu svesti na: metodologiju u tvorbi termina, upotrebu termina u kontekstu i nepoklapanje pojmovnih sistema, uz nerazumevanje odnosa među pojmovima. Kao rezultat ovih uticaja, javljaju se tri različita tipa polisemnih terminoloških jedinica.Ima termina koji istovremeno funkcionišu i kao reči opšteg fonda i kao termini, onih sa polisemantičkom strukturom koji se realizuju u više terminoloških sistema i onih sa polisemijom samo u svom zatvorenom terminološkom sistemu. Pored toga, termine možemo podeliti i na one koji su razvili višeznačnost u arapskom jeziku i na one kod kojih se polisemija javlja usled prevođenja sa drugih jezika.

\section{Literatura}

Cabré, M. T. (1999). Terminology: Theory, methods and applications, Amsterdam/Philadelphia: John Benjamins Publishing Company.

Dragićević, R. (2010). Leksikologija srpskogjezika. Beograd: Zavod za udžbenike.

Gortan-Premk, D. (2004). Polisemija i organizacija leksičkog sistema u srpskome jeziku. Beograd: Zavod za udžbenike i nastavna sredstva.

Šipka, D. (2006). Osnovi leksikologije i srodnih disciplina. Novi Sad: Matica Srpska.

Temmerman, R. (2000). Towards New Ways of Terminology Description: The sociocognitive-approach, Amsterdam: John Benjamins Publishing Company.

Vitas, D., Krstev, C. i Pavlović-Lažetić, G. (1996). Analiza jugoslovenskih terminoloških standarda sa područja informatike. U N. Vinaver (ur.), Standardizacija terminologije (str. 149-154). Beograd: SANU. 
Ivana Mali

\section{Summary}

\section{POLYSEMY IN ARABIC COMPUTER TERMINOLOGY}

This paper deals with polysemy of Arabic computer terms.Unlike traditional theory of terminology, which deals with "ideal" monosemous terms, we take the sociocognitive approach. In this modern approach to the study of terminology, polysemy is treated as normal. The corpus analysis of Arabic computer terms has shown that there are different reasons why polysemy occurs in terminology. They can be summarized as follows: the methodology used in terms' formation, the use of terms in context and the differences in conceptual systems, joined with misunderstanding of relations between concepts. As a consequence, there are three different types of polysemantic terms: those that have at least two meanings in computer terminology; those that have at least one meaning in computer terminology, and another meaning in some other terminology; and those that have at least one meaning in computer terminology and another in general language.

Key words: Arabic language, polysemy, computer terminology 